\title{
Reseña \\ Veiravé, D. (Comp.) , Corrientes, Editorial de la Universidad Nacional del Nordeste EUDENE, 2016, 182 pp.
}

\author{
Maia Milena Acuña*
}

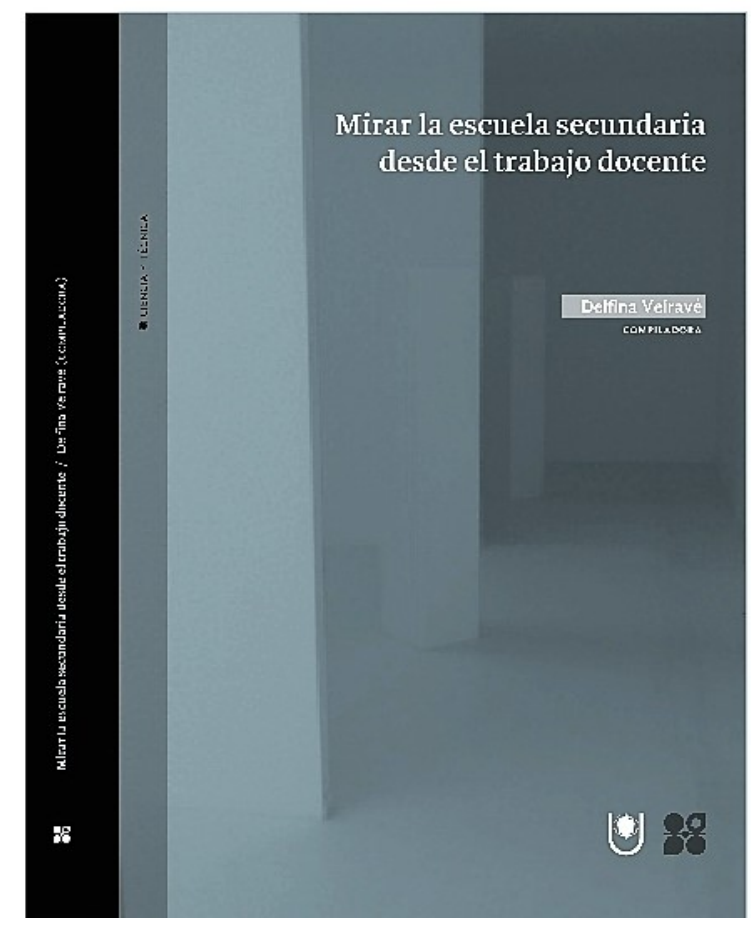

Disponible en la Editorial de la Universidad Nacional del Nordeste.

http://eudene.unne.edu.ar/

\footnotetext{
* Universidad Nacional del Nordeste - Facultad de Humanidades. Correo electrónico: maiaacunia@hotmail.com
} 
Mirar la escuela secundaria desde el trabajo docente se trata de un libro que nos invita a pensar el trabajo de los/las profesores/as desde la complejidad que encierra esta práctica social1 y que es llevado adelante por autores/as que, aun perteneciendo a diversas disciplinas, conjugan sus experiencias y las fusionan en la construcción de categorías de análisis abordadas desde diferentes niveles de producción del objeto de estudio: individual, institucional, del sistema educativo, las políticas y del contexto social más amplio. Esto ha implicado la adopción de un enfoque multirreferenciala que permite una lectura desde una heterogeneidad de perspectivas que demuestran cómo el trabajo docente se [re] configura en la cotidianidad escolar.

El texto reúne los resultados de una línea de investigación que, desde hace varios años, desarrolla un equipo integrado por docentes del Instituto de Ciencias de la Educación de la Facultad de Humanidades de la Universidad Nacional del Nordeste en la Argentina. Esta línea se centra en el análisis del Nivel Medio en la provincia del Chaco durante las últimas décadas.

El libro tiene como eje central el trabajo docente en el Nivel Medio, en torno a la formación y la identidad profesional de los/as docentes del nivel educativo de referencia, el impacto de las políticas educativas para el sector, las condiciones sociales, culturales y académicas que lo atraviesan, así como los sentidos construidos en la cotidianidad del mismo, donde se van definiendo las particularidades de la docencia conforme los contextos y las demandas que convergen en ella. Así, a lo largo de su recorrido, nos encontraremos con experiencias que se configuraron en escenarios socioterritoriales e institucionales diversos, situados en zonas urbanas, suburbanas y rurales, en una escuela intercultural bilingüe y una escuela agrotécnica.

Se inicia desde una definición amplia de trabajo docente, "refiriéndose al conjunto de funciones que despliega el/la profesor/a en relación con la enseñanza, los alumnos y las instituciones y las comunidades donde se desempeña, estén o no reconocidas formalmente en el puesto de trabajo por el cual reciben una remuneración" (p. 14). Al entender que se trata no sólo de una práctica histórico-social ligada a un modelo de análisis complejo, sino también a dos factores fundamentales: la objetividad, referida a los contextos de producción del trabajo, las formas en las que el/la docente se produce a sí mismo a través de tareas que despliega y que son consideradas de gran

1 Desde esta perspectiva, el trabajo del docente se vincula al de un agente que construye su experiencia con un margen de poder y autonomía en circunstancias que lo condicionan, pero que no lo [sobre] determinan (2016:15).

2 En términos de Ardoino (2005). 
relevancia para él -con respecto a la enseñanza, el aula, los alumnos, el currículum, la organización institucional y el sistema educativo- y la subjetividad, que alude a percepciones, valoraciones y actuaciones referentes a sucesos que los/as profesores/as van construyendo en su experiencia de formación y socialización.

De esta manera, conforme van transcurriendo los capítulos, el lector podrá advertir los nudos problemáticos que atraviesan el trabajo docente en las escuelas secundarias y aquella amplia definición -a la que se ha hecho referencia en líneas anteriores- cobrará un sentido mucho más elocuente.

En lo que refiere a los efectos de las políticas de reforma educativa en escuelas medias, Patricia Delgado en el capítulo 2 reconocerá que éstos no obedecen a medidas puntuales de una reforma particular, sino a rasgos recurrentes en las formas de hacer política educativa, encontrando continuidades en las modalidades de implementación, pero también reconociendo aspectos en los que las actuales políticas buscan diferenciarse de aquellas llevadas adelante en los años 90. Ella lo denomina "recontextualización", lo cual genera cierta tensión en el diario acontecer institucional.

Otro de los aspectos abordados trata de las configuraciones laborales en el trabajo docente; de aquellas tramas que lo van definiendo como tal, su complejidad -producto de la masificación, la diversificación y la fragmentacióny las dimensiones de la realidad que lo condicionan. Mariana Ojeda aborda esta temática desde una perspectiva sociológica -como también situacional e histórica- que plantea esta labor como un trabajo de socialización con otros, cuya construcción acontece en torno a ciertas condiciones: factores políticos, sociales, históricos, económicos, institucionales y subjetivos.

En el capítulo 4, Claudio Núñez narra en primera persona -compartiendo sus vivencias de formación y el discurso de profesores/as- las características que asume la identidad de los/as docentes como colectivo. Desde esta lectura, se destacan elementos vinculados a la complejidad en la construcción de dicha identidad: las situaciones y experiencias que atraviesan en sus vidas, sus espacios vitales y las prácticas y pensamientos que van tramando un sentido distinto de estar en la escuela.

Al poner en cuestión aquellos rasgos estructurales de la Escuela Media, Teresa Artieda, Yamila Liva y Soledad Almirón presentan en el capítulo 5 el análisis de un proyecto intercultural -el Bachillerato Libre para Adultos Bilingüe Intercultural- que ha venido a interpelar las dimensiones política, 
epistemológica, cultural y educativa del trabajo docente, apreciando desde las voces de profesores/as y miembros de la organización Qom y de la organización no indígena, los cuestionamientos a los modos tradicionales de organización, gobierno y gestión institucional. Se comparte aquí también las contribuciones, mixturas y contradicciones que, para la comunidad educativa, trajo consigo esta propuesta. En esta misma línea, lleana Ramírez, en el capítulo 6, realiza una caracterización respecto a la construcción de significados construidos en torno a la experiencia y a los desafíos de ser docente en la misma institución, cuya misión adopta un carácter de compromiso con la comunidad, con el fin de visibilizar y mantener viva la identidad cultural.

Al aportar nuevos sentidos y casi finalizando esta obra, Laura Rosso nos invita a indagar acerca del ¿Para qué educar en una escuela secundaria rural?, volviendo sobre lo explicitado en los discursos políticos-normativos y las voces de los profesores/as. Se evidencian aquí contradicciones entre las concepciones que éstos cargan consigo acerca de la comunidad, su participación, las prácticas institucionales llevadas adelante, los mecanismos y las opciones formativas definidas institucionalmente.

En síntesis, este libro recupera las significaciones y las traducciones particulares que se han ido generando colectivamente en el ámbito de las instituciones en torno al trabajo docente, expone una multiplicidad de sentidos acerca del conocimiento, las acciones, concepciones y negociaciones, y posibilita el análisis interpretativo y crítico de las condiciones históricas, sociales y culturales en las que se han construido los aspectos antes mencionados en torno al trabajo docente en el Nivel Medio.

Se destaca la relevancia de los autores para comprender las experiencias institucionales y particulares que van conformando la trama real en que la educación sucede. Una trama en permanente construcción, que articula historias personales, locales y colectivas (Ezpeleta y Rockwell, 1983: 2).

Desandar la historización y la configuración del quehacer docente es un modo de analizar lo complejo de este objeto de estudio, posibilitando la comprensión de sentidos construidos en su devenir: las prácticas y significados originados e instituidos por el accionar de los sujetos, las interacciones que constituyen la praxis docente; los principios generales según los cuales los sujetos organizan, en la vida cotidiana, sus experiencias cargadas de historias que los impregnan y que, al mismo tiempo, los interpelan; demanda e invita a romper con antiguos legados. 


\section{Bibliografía}

Ezpeleta J. y Rockwell E. (1983). La escuela: relato de un proceso de construcción teórica. São Paulo, Brasil: CLACSO. 